\title{
Implementation intentions in the entrepreneurial process: concept, empirical findings, and research agenda
}

\author{
Marco van Gelderen - Teemu Kautonen (D) \\ Joakim Wincent • Marina Biniari
}

Accepted: 11 December 2017 /Published online: 22 December 2017

(C) The Author(s) 2017. This article is an open access publication those confirming a strong intention to start a new business. We provide an in-depth discussion of the concept of implementation intention and an extensive research agenda.

Keywords Entrepreneurship · Entrepreneurial intentions · Entrepreneurial action · Entrepreneurial behavior - Implementation intentions

JEL classifications $\mathrm{L} 26 \cdot \mathrm{M} 13$

\section{Introduction}

The questions of why, when, and how some people but not others discover and exploit opportunities to create goods and services have long been core interests of the community of entrepreneurship scholars (Shane and Venkataraman 2000). The 1990s and the 2000s saw a surge in studies of what predicts and explains the differences between those exhibiting an intention to start their own business and those lacking such an intention (Schlaegel and Koenig 2014). The majority of those studies used models that predict actions from intentions, including the theory of planned behavior (Ajzen 1991, 2017) and the entrepreneurial event model (Shapero and Sokol 1982). Although both models include actions taken upon intentions as the ultimate dependent variable, the overwhelming majority of the research of the time focused solely on predicting and explaining intentions (Schlaegel and Koenig 2014). These studies

Aalto University, PO Box 15500, FI-00076 Aalto, Finland e-mail: marina.biniari@aalto.fi 
generated numerous valuable insights, yet left an incomplete picture, as new ventures are only created if intentions are followed by actions. Only recently have researchers begun to empirically investigate the link between entrepreneurial intentions and subsequent actions (Gielnik et al. 2014, 2015; Kautonen et al. 2015; Obschonka et al. 2015; Rauch and Hulsink 2015; Reuel Johnmark et al. 2016; Van Gelderen et al. 2015). These studies consistently find that a sizable proportion of people who express an intention to engage in start-up activity do not follow up on that intention with concrete actions.

The intention-action gaps found in prior studies raise questions over the relevance of research that merely focuses on entrepreneurial intentions. Even more importantly, they raise the question of what factors then determine whether intentions translate successfully into actions. Recent studies addressing the latter issue have examined action regulation. Gielnik et al. (2014) found that action planning - the degree of detail in the planning of future actionspositively moderates the relationship between entrepreneurial goal intentions and new venture creation up to 18 months after intentions are formed. Another example is provided by Van Gelderen et al. (2015), who found that the trait of self-control positively moderates the intention-action relationship. Both studies point to the importance of distinguishing goal setting (intention formation) from goal striving (intention implementation). In the latter process, variables involved in regulating actions play an important and distinct role.

The present study makes a theoretical contribution by extending entrepreneurial intention models with Gollwitzer's action phase theory $(1990,2012)$ and the concept of implementation intentions. This adds to our understanding of why some people successfully follow up on their intention to start a business, whereas others do not. We distinguish between the motivational and volitional phases in the course of taking action. According to action phase theory goal intention strength is only relevant to the motivational phases; effectiveness in taking action equally depends on self-regulatory strategies involved in the volitional phases concerned with goal implementation (Gollwitzer 2012). One such strategy, implementation intentions, supplements goal intention and specifies where, when, and how actions required to reach the goal will be taken (Gollwitzer 1999;
Hagger and Luzsczynska 2014; Sniehotta 2009). Apart from studies by Gielnik et al. (2014, 2015), who studied action planning in the form of the number of sub-steps and the precision of the timing of execution plans, implementation intentions have to the best of our knowledge not been explored in relation to entrepreneurial intentions and actions, despite scholars calling for such studies (Adam and Fayolle 2015; Carsrud and Brännback 2011; Fayolle 2013; Fayolle and Liñán 2014; Krueger 2009). Their effects have been studied extensively in social psychology, however. A meta-analysis by Gollwitzer and Sheeran (2006) showed that implementation intentions have a medium-to-large magnitude positive effect on goal attainment that extends beyond the effects of having goal intentions. Because prior studies are largely based on laboratory experiments and field studies involving straightforward goals and actions, we cannot assume the aforementioned effects can be replicated in the context of starting a new venture; which is a complex, uncertain endeavor undertaken in the medium-term that can take a variety of forms and involve a range of activities (Carter et al. 1996; Lichtenstein et al. 2007).

The present research analyzes the role of implementation intentions in taking entrepreneurial action using two waves of survey data drawn from the adult population of Sweden $(n=422)$, with a gap of 6 months between the expression of the intention to embark on starting a business, and an assessment of whether action had been taken, and if so, how much. We test and find support for a moderated mediation model in which implementation intentions mediate the effects of goal intentions on taking entrepreneurial action. Moreover, we find the mediation effect is even stronger for those with a high level of goal intention to engage in business gestation activity. Thus, our study supports the argument that variables related to action regulation play a major role in pursuing the goal of entrepreneurship. Moreover, the results complement the psychological literature on action regulation by providing empirical evidence on the applicability of implementation intentions to behaviors that can involve considerable uncertainty and a wide variety of activities performed in different sequences. The current study is an early attempt to investigate implementation intentions in the context of entrepreneurship, and consequently it concludes by providing an extensive research agenda. 


\section{Theory and hypotheses}

\subsection{Goal motivation and action regulation}

Many theories of motivation center around the notion of goals and their antecedents (e.g., Ajzen 1991; Carver and Scheier 1998; Fishbein and Ajzen 1975; Locke and Latham 1990; McClelland et al. 1953; Vroom 1964). For example, expectancy-value theory (Fishbein and Ajzen 1975) holds that people act on goals if they find the goal valuable, and if they anticipate taking actions that will fulfill the goal. Goals are mental representations of desired outcomes, and people are thought to form goal intentions, which are instructions to the self to act to secure those outcomes (Toli et al. 2016). The strength of a person's intention then determines whether he or she achieves that goal. This idea has found substantial empirical support. In a meta-analysis of meta-analyses studying the link between intention and subsequent behavior, intention strength explained $28 \%$ of the variance in behavior and had a sample weighted average correlation of 0.53 , which implies a strong substantive effect (Sheeran 2002).

However, in line with the proverb suggesting that "the road to hell is paved with good intentions," there is strong contrary evidence that goal intention strength alone is not always sufficient to reach the required goals (Gollwitzer and Sheeran 2006; Gollwitzer and Oettingen 2015; Sheeran 2002). First, the aforementioned correlation of 0.53 is driven to a considerable extent by non-intenders taking no action. According to Sheeran (2002), only $47 \%$ of those who have intentions subsequently take any action. Second, past behavior drives current behavior to a considerable extent. Entering goal intentions in the second step of the model estimation after controlling for past behavior resulted in just a $7 \%$ increment in the variance explained (Gollwitzer and Sheeran 2006). Finally, a metaanalysis of studies of intentions and behavior change in experimental settings, which rules out contextual variables being responsible for the observed associations, found that the effect of manipulating goal intention strength had only a small-to-medium effect size $(d=0.36$, which equates to R-squared $=0.03)$ (Webb and Sheeran 2006). In sum, the strength of goal intention appears less strongly related to taking action to achieve the goal than has been theorized.

Evidence for an intention-behavior gap has also been found in the realm of entrepreneurship research.
Considering that activities to start a new venture tend to be deliberate and intended as such (Bird 1988), and defining actions as intentional behavior (Greve 2001), we refer to entrepreneurial actions rather than behavior. A recent study of entrepreneurial intentions and actions by Kautonen et al. (2015) showed that goal intentions alone are often not sufficient for action to occur. In a study of the Austrian and Finnish working populations, the authors found that although intentions predicted a substantial amount of variance in the amount of start-up action taken, $63 \%$ of those with intentions had taken no or very little action when asked about the endeavor 1 year later. Nor are goal intentions sufficient to signal goal achievement: In a Ugandan sample, of those with intentions to undertake a set of five start-up activities, $55 \%$ had started their business after a 30 -month period, and the study reported a zero correlation between entrepreneurial goal intention strength and new venture creation (Gielnik et al. 2014).

Findings such as those above emphasize the importance of researchers going beyond the study of mere intentions to investigate how entrepreneurial goals translate into subsequent actions. Moreover, there are strong arguments that the association between intention and action in the entrepreneurial context will be even lower than the average association found in the other domains referred to earlier (Sheeran 2002). Much of the research on goals and subsequent behavior has considered simple, discrete goals and short-term tasks. In contrast, for the adult population aiming to start a business, the path from intention to action is complex, involves a mid-term time span, contains uncertainty, can take a variety of forms and activities, and can be influenced by and depend upon a host of intrapersonal and contextual factors (Carter et al. 1996; Lichtenstein et al. 2007). Under such conditions, the execution of entrepreneurial intentions can easily be derailed.

With the advent of modern self-regulation theories in the 1980 s, researchers started to examine whether goals and motivation alone might be insufficient to spur action (Brandstätter et al. 2003), and whether another framework could help explain the regulation of actions. One theory that attempts to offer a comprehensive view by analyzing both goal setting and self-regulatory processes is Gollwitzer's $(1990,2012)$ action phase theory. It identifies four action phases: the first and fourth phases are motivational and related to goal setting, whereas the second and third phases are volitional and concerned with what is termed goal striving and implementation 
(see Fig. 1, lower half). Each phase presents a different task for the individual to address (Gollwitzer 1990, 1999, 2012). The first of these tasks, which arises in the pre-decisional phase, requires individuals to decide which of their desires they really want to pursue. The formation of intentions takes center stage in this first phase. In the second phase, however, the focus is not on intentions. Then, the task is to initiate goal-directed action. Individuals in what are termed post-decisional and pre-actional phases have to determine how best to attain the chosen goal. In this phase, actions are planned that facilitate achieving the chosen goals. Having formulated an action plan, the individual enters what is termed the actional phase, and faces a third task, which is to ensure that the actions undertaken to achieve specific goals are successful. In the fourth phase, individuals review what they have achieved, while also contemplating future action (Achtziger and Gollwitzer 2008). The fourth phase may thus be followed by the first phase, lending this process model an iterative character. Progression from one phase to the next is not guaranteed, however, as each phase needs to be successfully concluded before the cycle can be completed.

The present study centers on the pre-actional second phase, which plays a pivotal role in translating goal motivation or intentions (phase one) into action (phase three) (see Fig. 1).

\subsection{Implementation intentions and taking entrepreneurial action}

In the pre-actional phase, actions are planned. Action planning is defined by Sniehotta et al. (2005: 567) as, "the process of linking goal-directed behaviors to certain environmental cues by specifying when, where, and how to act." Similarly, Gollwitzer (1996): 290) reports that in the pre-actional phase "individuals reflect and decide on the when, where, how and how long to act, thus creating plans for actions." Action planning thus results in implementation intentions, and many scholars use the terms action plan and implementation intention interchangeably (Adriaanse et al. 2011; BelangerGravel et al. 2013). However, much of the research evidence on implementation intentions is produced by Gollwitzer and colleagues (Gollwitzer 1999; Gollwitzer and Oettingen 2015; Gollwitzer and Sheeran 2006), who require implementation intentions to be formulated in an if-then format that specifies situational cues (when and where to act) and behavioral responses (how to act) in advance (Gollwitzer 1993, 1999). For example, when a prospective entrepreneur wishes to approach an identified financier at a networking function, the implementation intention might be formulated as: "I will attend this function and as soon as the financier is alone, I will approach and introduce myself." In this article, we use implementation intention in a wider sense than Gollwitzer did, in other words, an if-then structure is not compulsory. This is warranted because for those who form action plans or implementation intentions spontaneously, an if-then structure will often be implicit. Someone who starts a venture may implement an intention to register the business by planning to go to the Chamber of Commerce on Friday at 10 a.m.; it is unlikely that such a person will use the form: "If it is 10 a.m. on Friday, I will go to the Chamber of Commerce to register my business." In contrast, using an

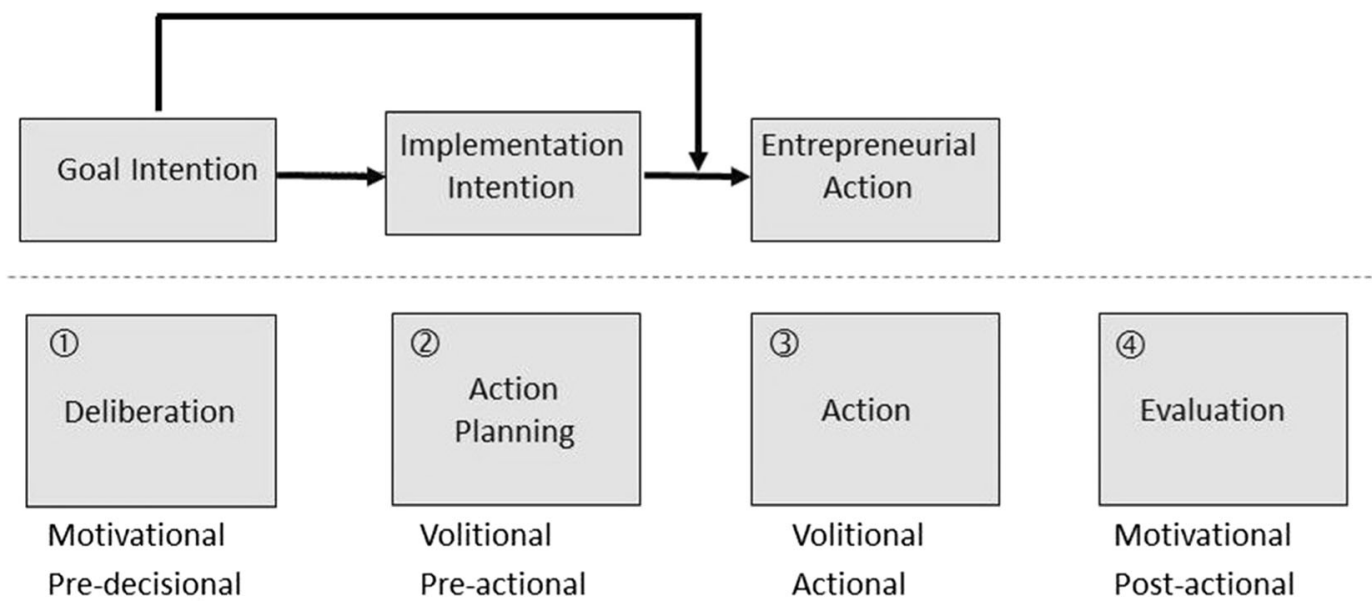

Fig. 1 Action phase model (below) and research model (above) 
explicit if-then structure is typically made mandatory in research experiments or in training sessions.

The research evidence to date shows that implementation intentions can facilitate the transition from goal intention to action (Carraro and Gaudreau 2013; Gollwitzer and Sheeran 2006). Gollwitzer and Sheeran's (2006) meta-analysis involved over 8000 participants in 94 independent studies and revealed a medium-to-large effect size $(d=0.65)$ of implementation intentions on goal attainment extending beyond the strength of the goal intention. Implementation intentions have been effectively applied to what Gollwitzer (2014) considers the most prominent challenges affecting goal attainment. These are getting started (the topic of the empirical work in this article); shielding the ongoing goal pursuit by staying on track in the face of competing goals, temptations, and distractions; calling a halt to unsuccessful efforts to reach a desired goal; and preserving energy for the pursuit of subsequent goals (Gollwitzer and Sheeran 2006; Gollwitzer 2014). Gollwitzer and Sheeran (2006) meta-analyzed whether implementation intentions help overcome three common obstacles to turning intentions into actions, also relevant to the entrepreneurship context. The first obstacle is losing sight of one's goal; the second is not seizing opportunities to act; and the third is a failure to disengage from a course of action when better options are available. With respect to overcoming these three obstacles, Gollwitzer and Sheeran (2006) found medium-to-large magnitude effect sizes for implementation intentions ( $d=0.54,0.61$, and 0.65 , respectively). The lists of challenges and obstacles that implementation intentions help to overcome suggest that implementation intentions can contain a wide variety of content, a topic we will discuss at length in our future research agenda.

Implementation intentions are effective because they heighten alertness to situational cues and automatize the behavioral response. The control of the action is passed from the person to the environment, which in turn frees the individual's cognitive processing capacity to deal with other aspects of the situation (Gollwitzer and Oettingen 2015). Forming implementation intentions activates the mental representation of specified cues (the if component). The situation specified in the if clause becomes cognitively activated and easily accessible from memory. If the cue occurs, the response (the then component) is thought to occur automatically (Gollwitzer and Sheeran 2006) and there is neuroscientific evidence to support this claim (Wieber et al. 2015). Accordingly, implementation intentions combine conscious planning and automatic response activation. The automaticity of the then-response is strategic, in the sense that it is based on an act of will (Thürmer et al. 2015), and implementation intentions can be said to be at the junction of controlled and automatic processes (Wieber and Gollwitzer 2017). Even if an if-then structure is not explicit, when implementation intentions (or action planning) are measured by the specification of when, where, and how to act in the service of one's intentions (Carraro and Gaudreau 2013), a contingent nature will often still be apparent as the "when" and "where" aspects are specified together with what action will be taken. The effectiveness of implementation intentions in a broader sense may thus also depend on the strategic automaticity engendered by a cue-response link. We return to the effectiveness of specific if-then formats in our research agenda (Section 6.4). We note at this point that implementation intentions, in whatever form, may also be effective for other reasons, for example because they stimulate commitment to the action (Ajzen et al. 2009; Fayolle and Liñán 2014) or reflection.

The construct of implementation intentions may help address the important theoretical question of why some people with strong entrepreneurial goal intentions fail to create a new venture. Recent meta-analyses in the health domain have shown that implementation intentions have a beneficial effect in both laboratory experiments and field settings (Adriaanse et al. 2011; BelangerGravel et al. 2013; Toli et al. 2016). However, the studies in health and other domains tend to concern settings that are quite unlike starting a venture, where attaining a goal can involve considerable uncertainty, and a wide variety of activities are performed in different sequences. Importantly, in the case of an overarching goal such as starting a business, intenders not only need to specify where and when they will perform a certain action, but also select the what, that is, the start-up activity on which they want to work. Of course, this adds a requirement to correctly identify the activities that will achieve a particular goal. A few field studies, however, do involve goals that could be achieved via several pathways, and they have found positive effects associated with implementation intentions. One such example is the study by Van Hooft et al. (2005), which found that implementation intentions were a significant predictor of subsequent job search behaviors. Based on 
the available evidence on the effectiveness of implementation intentions, we expect that they have a positive effect on taking entrepreneurial action. But what influences the emergence of implementation intentions?

The majority of studies in the implementation intention literature involve research designs where the implementation intentions are induced, either by the researcher or by the organization or entity that conducts an intervention (Prestwich et al. 2015). An example of the latter would be a training in which participants are trained and then instructed to form implementation intentions, and then the amount of action taken by this group is compared to a control group. As a consequence, less research has been done on those antecedents of implementation intentions that arise naturally. The few studies that do study non-induced, self-generated, spontaneous implementation intentions invariably show that their occurrence is best predicted by goal intention strength (Brickell et al. 2006; Churchill and Jessop 2010; Rise et al. 2003). A meta-analysis in the health domain by Carraro and Gaudreau (2013) involving a range of types of action planning confirms the mediating nature of action planning. The same study explains that once individuals intend to pursue a goal, they may spontaneously create action and coping plans to help them with the logistics of goal striving and to protect their intentions against temptations, obstacles, and distractions. Similarly, Wieber and Gollwitzer (2017) argue that goals and means are connected, and that the activation of a mental representation of a goal should also activate the mental representation of suitable means to pursue that goal.

The action phase model guiding our study also clearly shows that implementation intentions arise as a consequence of goal intention strength. If implementation intentions are formed, they must have been preceded by a goal intention. Implementation intentions are always in the service of goal intentions, and do not exist in and of themselves. Of course, it is possible that someone takes certain actions that eventually lead to a new venture, and uses implementation intentions in the process, but these implementation intentions can then not be entrepreneurial implementation intentions to the actor (although they could be labeled as such at a later stage or by an outside observer), because the goal that the actions served was not an entrepreneurial goal. In sum, according to the action phase model, goal intentions do not necessarily translate into implementation intentions, and in that case the second phase will not be completed, and the action will not be undertaken. However, if implementation intentions are formed, they are a consequence of goal intentions. Hence, we hypothesize:

\section{H1 Implementation intention mediates the effect of the goal intention to engage in business start-up activities on subsequent entrepreneurial action.}

We further hypothesize that the effect of implementation intention is contingent upon the strength of goal intention. Sheeran et al. (2005) studied the interplay between goal intentions and implementation intentions and found that when participants had weak goal intentions, implementation intentions had no impact on behavioral performance. Prestwich et al. (2015) and Gollwitzer and Sheeran (2006) similarly concluded that implementation intentions benefit goal achievement only when if-then plans are underpinned by strong goal intentions. It is not evident that our study will deliver a similar result. First, studies in the Gollwitzer tradition almost invariably involve research designs, whether in the lab or in the field, where the implementation intentions are induced, and where goal intention strength among participants varies considerably. In contrast, we study non-induced, spontaneous, self-generated implementation intentions as they occur naturally among people with an interest in starting a venture. As implementation intentions always serve goal intentions, we do not study those without any interest in starting a venture. As a consequence, all participants are at least somewhat motivated. Secondly, studies that adopt a broader conception of action planning than implementation intentions in the Gollwitzer tradition indicate that such action plans can also be beneficial when goal intention strength is relatively low (Carraro and Gaudreau 2013; Schüz et al. 2008). It is possible to discern an augmentation and a substitution effect. With an augmentation effect, goal intentions moderate the impact of implementation intentions on goal attainment such that strong effects of implementation intentions emerge when participants hold strong goal intentions. With a substitution effect, implementation intentions help the aspiring entrepreneur take action, even if the level of motivation for the goal was moderate. Because of the automaticity engendered by the coupling of the what, when, and where aspects of action, actions may be taken even if intention strength is relatively low. 
The finding that implementation intentions foster action even at moderate levels of entrepreneurial goal intentions is important because nascent entrepreneurship activities can be seen as experimenting, information finding, opportunity shaping, and opportunity enactment. Taking action can therefore increase motivation (the fourth and concluding phase of the action phase model is once again motivational), or lead to a justified conclusion that it is better not to start the venture (Davidsson 2006; Gartner et al. 2003). Without action, it would be difficult to reach this conclusion, and arriving at a conclusion is generally better than lingering in the intention mode. We therefore expect implementation intentions to be effective at both high and moderate levels of goal intention strength. Nevertheless, we expect the relation between implementation intentions and action to be stronger for those with stronger goal intentions, because this group benefits from having both high motivation and an action plan. This expectation is in line with the results of Gielnik et al. (2014, 2015), who found that action planning (measured as the level of detail in action plans) positively moderated the effect of goal intentions on subsequent action. Against this backdrop, we propose:

H2 Goal intention strength moderates the positive relationship between implementation intentions and subsequent entrepreneurial action, such that the relationship is stronger when goal intention strength is high.

\section{Data and method}

\subsection{Data collection}

We collected two waves of survey data using the proprietary M3Panel for Sweden, which is representative of the Swedish adult population. The questionnaire was administered online in May (wave 1) and November (wave 2) of 2015. Potential respondents were chosen using random sampling from the pool of individuals aged 18 to 70 in the M3Panel. The survey was clearly labeled as academic research related to work and entrepreneurship. Invitations to participate in the study were sent to 3500 individuals, of whom 2092 responded (response rate: $60 \%$ ).
To minimize common method bias, the respondents were assured they were contributing anonymously and the order of the questions was also counterbalanced (Podsakoff et al. 2003). Furthermore, we took measures to avoid nonresponse bias by establishing the importance of the survey and keeping the questionnaire short (Yu and Cooper 1983). Pilot testing indicated the full questionnaire would take only around 5 to $6 \mathrm{~min}$ to complete. We also assessed the sample of 2092 individuals for potential nonresponse bias using archival analysis (Rogelberg and Stanton 2007). This involved comparing the characteristics of the sample with the characteristics of the population. We compared the gender and age distribution in the sample with the national distribution in the same age range based on the official Swedish population statistics. Based on this analysis, nonresponse bias does not seem to be a major issue in our sample.

The survey began with a few demographic questions followed by some on the respondent's employment status and intentions to commence activity to start a business in the next 6 months. Individuals who were self-employed or who had already taken concrete actions to start a business (nascent entrepreneurs) were excluded from the study. Those without any level of interest in starting a business in the next 6 months were also excluded, because implementation intentions are only likely to be effective among participants who have set a relevant goal (Gollwitzer and Oettingen 2015; Sheeran et al. 2005). Thus, the sample used in this analysis includes those respondents who had some level of intention to engage in business gestation activity in the next 6 months, but who had not yet taken action upon that intention. Questions concerning implementation intentions and a number of other relevant variables were posed to the 903 respondents who reported an interest in engaging in start-up activity in the following 6 months (based on the measure for goal intention strength; see Section 3.2.3).

Six months later, those 903 individuals were invited to participate in a follow-up survey which inquired whether and to what extent the respondents had engaged in start-up activity. We received 450 responses in wave 2 (response rate: $50 \%$ ). After discarding 28 observations due to missing values, the final sample used in the regression analysis comprises data from 422 individuals. All independent and control variables were measured in wave 1 , whereas the dependent variables were measured in wave 2 . 


\subsection{Measures}

\subsubsection{Action}

In order to ensure the robustness of our results, we used two different approaches to operationalizing entrepreneurial action. The first approach operationalized action as the magnitude of effort expended to achieve the goal of starting a business, rather than the achievement of the outcome of having started a business. This aligns with the approach adopted by Kautonen et al. (2015) who closely followed Ajzen's (2017) recommendations for operationalizing intention and action in the theory of planned behavior. Our data contain two measures for the magnitude of effort: the average number of hours spent weekly on the start-up in the preceding 6 months (five categories; Table 1) and the amount of start-up related action taken in the preceding 6 months (none at all, some, quite a lot, or very much). Because these two measures are highly correlated (Spearman's rho= 0.88 ) and produced nearly identical results, for parsimony we only report the results pertaining to the average number of hours spent weekly.

Although operationalizing action as the magnitude of effort accords with established theory on intention and action (Ajzen 2017), we also included measures of goal achievement in our survey. This is because aspiring entrepreneurs can expend effort without making much progress with their ventures, and thus understanding whether implementation intentions lead to productive action is relevant in the entrepreneurial context. We captured goal achievement by asking the respondents to assess the progress made with their intended venture in the last 6 months. First, we asked them which stage their venture project was at when wave 2 of the survey was conducted. The respondents chose from no action at all to having established a fully operational business (five categories; Table 1). Second, we asked them to evaluate the extent of progress made and their success in progressing the intended business in the preceding 6 months with two respective 6-point rating scale items (Cronbach's alpha: 0.90). The two measures of progress are highly correlated (Spearman's rho = 0.81 ) and generate virtually identical results in regression analysis. Therefore, in the interests of parsimony, we opted to use only the ordinal measure in the analysis.
Table 1 Descriptive statistics

\begin{tabular}{|c|c|c|}
\hline Variable & Mean & SD \\
\hline \multicolumn{3}{|l|}{$\begin{array}{l}\text { Action: Average number of weekly hours spent } \\
\text { on the intended start-up activity in the } \\
\text { last } 6 \text { months }\left(\mathrm{t}_{2}\right)\end{array}$} \\
\hline $0 \mathrm{~h}$ & .30 & \\
\hline $1 \mathrm{~h}$ or less & .23 & \\
\hline 2 to $5 \mathrm{~h}$ & .26 & \\
\hline 6 to $10 \mathrm{~h}$ & .09 & \\
\hline 11 or more hours & .11 & \\
\hline \multicolumn{3}{|l|}{$\begin{array}{l}\text { Action: Progress made with the start-up activity } \\
\text { in the last } 6 \text { months }\left(\mathrm{t}_{2}\right)\end{array}$} \\
\hline No action taken & .30 & \\
\hline $\begin{array}{l}\text { Some action taken, but the individual considers } \\
\text { giving the idea up }\end{array}$ & .17 & \\
\hline $\begin{array}{l}\text { Quite a bit of work left to do before the business } \\
\text { is fully operational }\end{array}$ & .37 & \\
\hline Business is getting close to being operational & .09 & \\
\hline Business is up and running & .07 & \\
\hline $\begin{array}{l}\text { Implementation intention (index of } 3 \text { items; range } \\
1-6 \text {; Cronbach's alpha } .88)\left(\mathrm{t}_{1}\right)\end{array}$ & 3.41 & 1.21 \\
\hline $\begin{array}{l}\text { Goal intention strength }(1=\text { pretty sure/definitely; } \\
0=\text { perhaps but not sure yet })\left(t_{1}\right)\end{array}$ & .19 & \\
\hline $\begin{array}{l}\text { Prior entrepreneurial experience }(1=\text { yes; } 0=\text { no }) \\
\left(t_{1}\right)\end{array}$ & .25 & \\
\hline \multicolumn{3}{|l|}{$\begin{array}{l}\text { Intention duration: How long respondent has had } \\
\text { an intention to start a business }\left(t_{1}\right)\end{array}$} \\
\hline $0-3$ months & .12 & \\
\hline 4-6 months & .20 & \\
\hline $7-12$ months & .18 & \\
\hline More than a year & .50 & \\
\hline \multicolumn{3}{|l|}{ Aim of the intended business $\left(t_{1}\right)$} \\
\hline Part-time & .47 & \\
\hline Employ oneself & .20 & \\
\hline Employ a few people but not grow & .22 & \\
\hline Invest and grow & .10 & \\
\hline Female $\left(t_{1}\right)$ & .51 & \\
\hline Age (range: 18 to 70 years) $\left(\mathrm{t}_{1}\right)$ & 43.42 & 14.51 \\
\hline Higher education degree $\left(t_{1}\right)$ & .33 & \\
\hline
\end{tabular}

Notes: $n=422 . \mathrm{SD}=$ standard deviation. $\mathrm{t}_{1}$ and $\mathrm{t}_{2}$ refer to the variable having been measured in wave 1 or wave 2 of the survey, respectively

\subsubsection{Implementation intention}

The measurement scale for implementation intention used a 6-point Likert format anchored with strongly disagree (1) and strongly agree (6) from Ziegelmann et al. (2007) that was adapted to the context of new venture creation. It comprises three items: "I have 
already planned precisely what I will do as my first step to starting a business"; "I have already planned precisely when to engage in my first step to starting a business"; and "I have already planned precisely where to engage in my first step to starting a business" (Cronbach's alpha: 0.88).

\subsubsection{Goal intention strength}

We measured the intention to engage in business startup activity by asking the respondent: "Do you intend to take steps to start a business in the next 6 months?" Those who responded "definitely not" were excluded from the present study because our research focuses on whether and to what extent people with entrepreneurial intentions act on those intentions. The remaining responses were coded into a dummy where 0 stands for "perhaps I will but I am not yet sure" and 1 stands for "I am pretty sure/I definitely will." We combined the two categories indicating higher levels of intention because of the low frequency of responses in the highest category. We interpret a zero categorization as indicating an interest in starting a business, whereas a categorization of one indicates an actual intention to act to start one. Because this variable measures the strength of the intention instead of the presence or absence of an intention to engage in start-up activity, we refer to the variable as goal intention strength.

\subsubsection{Control variables}

The regression models include several control variables that, ex ante and based on prior research, influence either the dependent variables or the dependent and the independent variables. Prior entrepreneurial experience is operationalized as a dummy where 0 stands for no prior start-up experience, whereas 1 means that the individual has been involved in one or more start-ups prior to that currently considered. Previous studies associate having previous experience from start-up activities with a greater likelihood of acting upon entrepreneurial intentions (Van Gelderen et al. 2015; see Conner and Armitage 1998 for meta-analytic evidence on a more general positive relationship between past experience and acting on intentions). Intention duration was operationalized as the number of months the individual had held the intention to commence start-up activities. Because the initial sample was collected at a single point in time, participants varied in terms of how long they had held their intention, which may affect the intentionaction relationship. We further followed Kautonen et al. (2015) in controlling for the type of business activity to which the start-up intention pertains. Here, we distinguish between intended start-ups targeting a part-time business; a sole proprietorship employing only the founder; a small business employing a few people; or a business into which the aspiring entrepreneur intends to invest for growth. Finally, based on prior empirical evidence (Parker 2009), we included gender, age, and educational attainment as further control variables.

\subsection{Sample characteristics}

Table 1 presents descriptive statistics for all variables in the study. The action variables highlight a substantial gap between intention and action, similar to prior research on the entrepreneurial intention-action relationship (Gielnik et al. 2014; Kautonen et al. 2015). Most individuals in the sample either did not take any action $(30 \%)$ or took very little action $(23 \%$ spent $1 \mathrm{~h}$ or less per week on start-up activity). In addition, $16 \%$ reported their business was fully operational or close to being operational. These findings support the importance of variables that influence translating goal setting into goal striving. Table 2 displays the correlation matrix. Because the dependent variables, intention duration, and business aim are ordinal variables, the matrix reports Spearman's rank correlation coefficients. It is worth noting that although the dependent variables capture different facets of entrepreneurial action-magnitude of action and progress made toward the goal- their inter-correlation is high at 0.79 .

\section{Results}

Our hypotheses imply mediation and moderation effects, such that implementation intentions are proposed to mediate the effect of goal intention strength on taking action (H1), while at the same time, goal intention strength is hypothesized to moderate the effect of implementation intentions on taking action (H2). We opted for path analysis with maximum-likelihood estimation to test our hypotheses. This technique makes it possible to test mediating and moderating effects in a single model (Williams et al. 2009). Because the dependent variables capturing action are measured on ordinal scales, we specified the respective structural equations 
Table 2 Correlation matrix

\begin{tabular}{|c|c|c|c|c|c|c|c|c|c|}
\hline Variable & 1. & 2. & 3. & 4. & 5. & 6. & 7. & 8. & 9. \\
\hline 1. Action (weekly hours) $\left(\mathrm{t}_{2}\right)$ & 1 & & & & & & & & \\
\hline 2. Action (progress with start-up) $\left(t_{2}\right)$ & $.79 *$ & 1 & & & & & & & \\
\hline 3. Implementation intention $\left(t_{1}\right)$ & $.43 *$ & $.46^{*}$ & 1 & & & & & & \\
\hline 4. Goal intention strength $\left(t_{1}\right)$ & $.33^{*}$ & $.33^{*}$ & $.42 *$ & 1 & & & & & \\
\hline 5. Prior entrepreneurial experience $\left(t_{1}\right)$ & -.00 & -.02 & .07 & .02 & 1 & & & & \\
\hline 6. Intention duration $\left(t_{1}\right)$ & $-.31 *$ & $-.33 *$ & $-.37 *$ & $-.29 *$ & -.08 & 1 & & & \\
\hline 7. Aim of the intended business $\left(t_{1}\right)$ & .04 & .02 & .00 & -.00 & -.03 & -.02 & 1 & & \\
\hline 8. Female $\left(t_{1}\right)$ & .02 & -.06 & $-.14 *$ & .04 & -.03 & -.05 & -.00 & 1 & \\
\hline 9. Age $\left(t_{1}\right)$ & $-.24 *$ & $-.19^{*}$ & -.08 & $-.14 *$ & $.24 *$ & $.30 *$ & $-.16^{*}$ & $-.19 *$ & 1 \\
\hline 10. Higher education degree $\left(t_{1}\right)$ & -.02 & -.07 & -.03 & -.05 & .01 & .07 & .01 & $.04 *$ & .05 \\
\hline
\end{tabular}

Notes: $n=422$. Spearman's rhos. $* p<.05 . \mathrm{t}_{1}$ and $\mathrm{t}_{2}$ refer to the variable having been measured in wave 1 or wave 2 of the survey, respectively

as ordinal logit regressions. We examined the models for multicollinearity and influential observations but did not find any evidence to suggest that either of these issues would be a problem in our analysis.

The first column in Table 3 reports the estimates of the equation pertaining to the mediator in the path model: implementation intention. Not surprisingly, a high level of implementation intention is significantly associated with a high level of goal intention strength. Because the results pertaining to implementation intention are identical across the different path models (the models we estimated vary only in the equation pertaining to the dependent variable), for parsimony we only report these estimates once in Table 3. The remaining columns therefore report the estimates of the structural equation pertaining to action from different model specifications. In Models 1 and 2, the dependent variable is the number of hours spent on start-up activities each week, whereas the dependent variable in Models 3 and 4 is progress with the new venture project. Models 1 and 3 present the unconditional effects, while Models 2 and 4 add the interaction between goal intention strength and implementation intention to the equation pertaining to action.

Models 1 and 3 show that implementation intention exerts a positive and significant effect on action. This effect is similar for both operationalizations of entrepreneurial action, an outcome that supports the robustness of the finding. The results also indicate that goal intention strength is positively and significantly associated with action. Using the estimates in Models 1 and 3, and also the column pertaining to implementation intention in Table 3, we computed the indirect effect of goal intention strength on action via implementation intention. For Model 1, the indirect effect is $0.67(p<0.001)$ and for Model 3, it is $0.75(p<0.001)$. The indirect effects constitute 45 and $48 \%$ of the total effect of goal intention strength on action (computed as the sum of the indirect and direct effects) in Models 1 and 3, respectively. We therefore conclude that the effect of goal intention strength on action is partially and significantly mediated by implementation intention, and accordingly, we find support for Hypothesis 1.

Models 2 and 4 include an interaction between implementation intention and goal intention strength to test Hypothesis 2, which proposed that goal intention strength moderates the relationship between implementation intention and action. The interaction term is positive and significant for both action measures. This means that the effect of implementation intention on taking action is stronger when the individual has a high level of goal intention strength and weaker when the level of goal intention strength is low (Aiken and West 1991). Thus, Hypothesis 2 is supported. Figure 2 illustrates the interaction effect for Model 2 where the dependent variable is the number of weekly hours spent on start-up activities. The finding is robust against the other action variable: the graph for Model 4, featuring progress made with the start-up as the dependent variable, is virtually identical to the one depicted in Fig. 2 (this graph is available from the authors upon request).

Support for Hypothesis 2 means that the mediation effect in Hypothesis 1 examined above needs to be 
Table 3 Path-model estimates

Mediator: Implementation intention $\left(\mathrm{t}_{1}\right)^{1}$
Dependent variable: Action (weekly hours) $\left(\mathrm{t}_{2}\right)$

(1)

(2)

\begin{tabular}{|c|c|c|c|c|c|}
\hline Implementation intention (II) $\left(t_{1}\right)$ & & $.60 * * *(.09)$ & $53 * * *(.10)$ & $.67 * * *(.10)$ & $.55 * * *(.10)$ \\
\hline Goal intention strength $\left(t_{1}\right)$ & $1.11 * * *(.14)$ & $.83 * *(.26)$ & $.37(.34)$ & $.80 * *(.27)$ & $.13(.34)$ \\
\hline II * goal intention strength & & & $.61 *(.28)$ & & $.88 * *(.28)$ \\
\hline Prior entrepreneurial experience $\left(t_{1}\right)$ & $.09(.12)$ & $.09(.22)$ & $.11(.22)$ & $-.12(.23)$ & $-.09(.22)$ \\
\hline \multicolumn{6}{|c|}{ Intention duration (base: more than a year) $\left(t_{1}\right)$} \\
\hline $0-3$ months & $.61 * * *(.17)$ & $.82 * *(.31)$ & $.69 *(.32)$ & $1.07 * *(.33)$ & $.89 * *(.33)$ \\
\hline 4-6 months & $.76 * * *(.14)$ & $.31(.26)$ & $.34(.26)$ & $.56 *(.27)$ & $.64 *(.27)$ \\
\hline $7-12$ months & $.47 * *(.14)$ & $.30(.25)$ & $.33(.25)$ & $.36(.26)$ & $.43(.26)$ \\
\hline \multicolumn{6}{|c|}{ Aim of the intended business (base: part-time) $\left(t_{1}\right)$} \\
\hline Employ oneself & $.23(.14)$ & $.07(.25)$ & $.16(.25)$ & $.18(.25)$ & $.32(.26)$ \\
\hline Employ a few people but not grow & $-.15(.13)$ & $-.20(.25)$ & $-.11(.25)$ & $-.49(.25)$ & $-.35(.25)$ \\
\hline Invest and grow & $.09(.17)$ & $.11(.29)$ & $.12(.29)$ & $.20(.31)$ & $.26(.31)$ \\
\hline Female $\left(t_{1}\right)$ & $-.38 * * *(.10)$ & $.07(.19)$ & $.06(.19)$ & $-.26(.19)$ & $-.27(.19)$ \\
\hline Age $\left(t_{1}\right)$ & $.00(.00)$ & $-.02 * *(.01)$ & $-.02 * *(.01)$ & $-.02 *(.01)$ & $-.02 *(.01)$ \\
\hline Age squared & $.00(.00)$ & $-.00(.00)$ & $-.00(.00)$ & $-.00 *(.00)$ & $-.00 *(.00)$ \\
\hline Higher education degree $\left(t_{1}\right)$ & $.00(.11)$ & $.01(.19)$ & $.00(.19)$ & $-.29(.20)$ & $-.29(.20)$ \\
\hline R-squared & .28 & .30 & .31 & .35 & .37 \\
\hline Log likelihood & & -1181.18 & -1178.78 & -1135.71 & -1130.41 \\
\hline
\end{tabular}

Notes: $n=422$. Maximum-likelihood estimates. Threshold and intercept estimates not reported

${ }^{1}$ Because the estimates pertaining to implementation intention are identical across the four path-model specifications, these results are reported only once

The column pertaining to implementation intention reports linear path-model coefficients and their standard errors. The columns pertaining to action report logit coefficients and their standard errors. The R-squared in these columns is the McKelvey and Zavoina pseudo R-squared. Implementation intention and age are mean-centered. $t_{1}$ and $t_{2}$ refer to the variable having been measured in wave 1 or wave 2 of the survey, respectively

$* p<.05, * * p<.01, * * * p<.001$ (two-tailed)

adjusted to account for the significant moderation. To do so, we computed moderated mediation effects following the procedures outlined by Hayes (2013). Figure 3 displays the indirect effect of goal intention strength on taking action for Model 2. Again, the result for the other dependent variable (in Model 4) is virtually identical, supporting the robustness of the finding (the graph is available from the authors upon request). The indirect effect is adjusted in such a way that the relationship between implementation intention and action is moderated by goal intention strength. The indirect effect of goal intention strength is positive and significant $(p<0.001)$ at both levels of goal intention strength. But as Fig. 3 shows, the indirect effect is stronger when goal intention strength is high.

Finally, we examined the robustness of our results by comparing novice and experienced entrepreneurs and also men and women. We did this by adding respective higher-order interaction terms (implementation intention * goal intention strength * prior entrepreneurial experience/gender) to the equations pertaining to action in Models 2 and 4. Similarly, we added an interaction between goal intention strength and experience/gender to the equations pertaining to implementation intention in Models 2 and 4. The additional interactions were clearly non-significant, suggesting that prior entrepreneurial 
Fig. 2 Effect of implementation intention (measured in wave 1) on action (hours expended weekly; measured in wave 26 months later) for low and high levels of goal intention strength

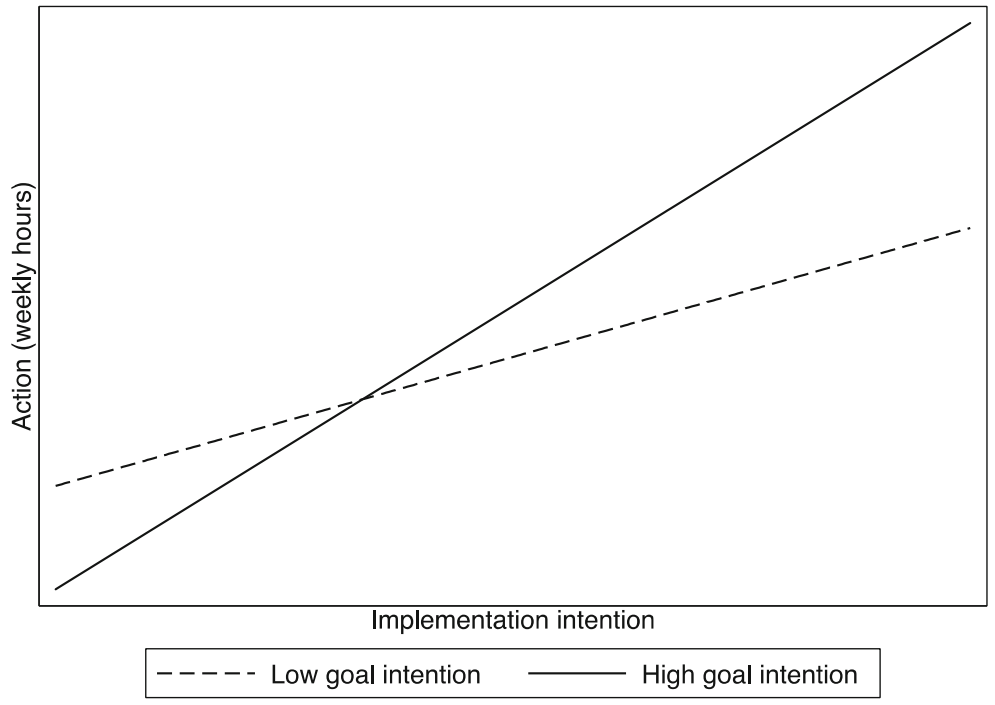

experience and gender do not influence the relationships between implementation intention, goal intention strength, and action.

\section{Discussion}

Consistent with prior research on the intention-action relationship in the context of new venture creation (Gielnik et al. 2014; Kautonen et al. 2015), the present study reveals a considerable gap between the formation of intentions and the realization of those intentions. Of the 422 respondents in our study who had some level of intention to commence activities to progress starting their own business, 30\% took no action and a further $23 \%$ spent less than $1 \mathrm{~h}$ per week on start-up activities in the subsequent 6 -month period. Moreover, only $16 \%$ of the respondents reported having a business that was either fully operational or close to being so. The results highlight the relevance of implementation intentions to taking entrepreneurial action, and add to the body of evidence showing that variables that advance effective action regulation play an important role in achieving entrepreneurial goals (Gielnik et al. 2014, 2015; Van Gelderen et al. 2015). Entrepreneurial goals involve hierarchies of single acts undertaken in specific situational contexts involving deadlines or windows of opportunity, and our findings indicate how important it is
Fig. 3 Indirect effect of goal intention strength (measured in wave 1 ) on action (weekly hours; measured in wave 26 months later) via implementation intention (measured in wave 1)

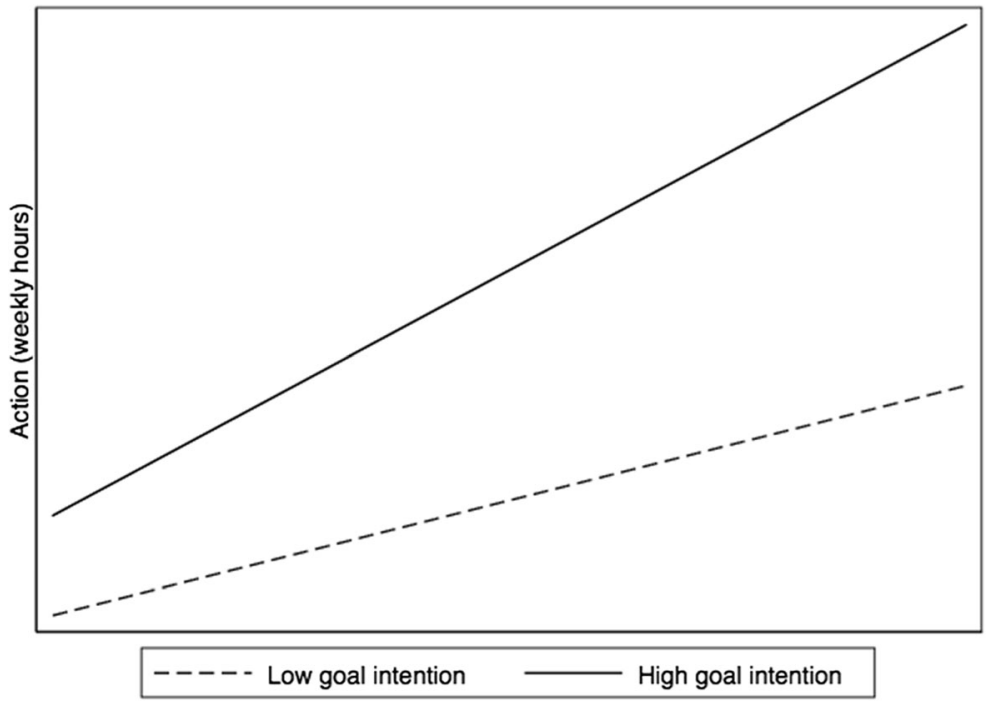


to identify both the means (responses) and the context (internal or external cues) that will permit intentions to be realized. Moreover, whereas studies addressing implementation intentions tend to reveal that they are only effective when the person concerned also has strong goal intentions (Gollwitzer and Sheeran 2006; Sheeran et al. 2005), our results indicate that implementation intentions can also be effective in cases when a person's goal intentions are not particularly strong. This finding echoes those on action planning generally (Carraro and Gaudreau 2013; Schüz et al. 2008).

More generally, our results highlight the importance of theorizing beyond a simple intention-behavior link. The theory of action phases helps understand why some people do not act on their intentions: if individuals do not transition to the pre-actional phase because they do not prepare for their actions through implementation intentions, they are less likely to enter the more advanced action phases and then less likely to achieve their goal. Because implementation intentions constitute a form of planning, our results support the importance of planning in creating a new venture. The concept of planning has been criticized in the scholarly and practitioner literature, which increasingly acknowledges the importance of flexibility, intuition, affect, improvisation, and effectuation in the entrepreneurial process (Frese et al. 2015; Lerner et al. 2018). Indeed, entrepreneurial actions can be non-routine, have multiple objectives that can be pursued in different sequences, and be performed in the context of uncertainty. The discussion of planning, however, is focused primarily at the formal venture-level (Brinckmann et al. 2010; Honig 2004; Sarasvathy 2001) at the cost of overlooking the fact that even in flexible, intuitive, affective, improvisational, and effectual approaches, actions are still regulated, and can benefit from improved regulation. We return to this issue when outlining future research directions in the next section.

Readers might question whether it is necessarily a good thing that entrepreneurial intentions always translate into actions, for example, if a person's personality structure shows a poor fit with entrepreneurial endeavors (Obschonka and Stuetzer 2017). However, discovering that this is the case is not incompatible with forming and acting on implementation intentions. First, actions may be taken to evaluate the desirability and feasibility of a new venture rather than starting a business per se. Second, the action phase model has a fourth phase, evaluation, which we do not study, but which proposes that after finishing an action, a new motivational phase ensues, during which individuals consider their next step. Here aspects of desirability, feasibility, and norms are reconsidered. Third, implementation intentions are not necessarily concerned with initiating action, and might instead be concerned with timely disengagement from a course of action (e.g., "if taking steps to start a new venture makes me feel uncomfortable for five consecutive days, then I will cease my start-up activities.") (Gollwitzer 2014; Gollwitzer et al. 2008).

The present study's results add to the literature on implementation intentions by showing their effectiveness in the context of setting up a new venture. However, the form of implementation intentions in this study is somewhat different from that suggested in typical studies of implementation intentions, which predominantly concern relatively simple and discrete behaviors, whether in laboratory or field settings. In starting a new business, the prospective entrepreneur must first decide what action he or she will take and how, before deciding when and where to engage in that action. Moreover, the 6-month time frame used in this study means the situational cues were specified at a relatively general level. Nevertheless, the present study's results demonstrate that even in these applied conditions, implementation intentions are still effective. One reason for that may be that situational cues within implementation intentions are not necessarily specific in terms of time and place (such as calling supplier X from the office on day Z), but can also support passive search and alertness, a point we will explore further in our research agenda below.

\section{Research agenda}

The empirical study of implementation intentions in the context of entrepreneurship is relatively new, and consequently there are numerous opportunities for scholars to advance the understanding of the topic, some of which we present below. Moreover, several of the following suggestions will address the limitations of the present study.

\subsection{Variations in implementation intention content}

Implementation intentions can involve $a$ wide variety of content, and effectiveness in the context of 
entrepreneurship may vary from one type to the next. This applies to the volitional problem that the implementation intention helps to overcome, as well as the if and the then components of the implementation intention. Volitional problems relating to goal achievement might include the initiation of actions, the continued pursuit of actions (e.g., guarding against distractions), the termination of actions (if better alternatives arise), or the transition toward taking follow-up action (Gollwitzer 2014). Our study only addressed action initiation, and future research might consider the effectiveness of implementation intentions with respect to these other volitional issues occurring later in the entrepreneurial process.

Furthermore, future research could consider various types of "then" responses. For example, Prestwich et al. (2015) distinguish between response-facilitating, replacement, distraction-inhibiting, and negation implementation intentions. Our empirical work merely focuses on response-facilitating implementation intentions. Other types of implementation intentions may be relevant for behaviors that hinder the initiation and execution of the start-up process. For example, watching television or playing video games can divert time, energy, and attention from entrepreneurial action. Therefore, implementation intentions may not only be framed with regard to entrepreneurial actions, but might also reference barriers and distractions that jeopardize goal completion. The situational cues that trigger counterproductive habits may be specified in the if component of implementation intentions, along with an appropriate response (cf. the concept of coping planning, Carrero and Gaudreau, 2013).

It should be noted that the then component does not necessarily refer to actions, but can also address cognitions or emotions. For example, Thürmer et al. (2015) find facilitating, reflecting, suppression, and prioritization implementation intentions influential in organizational contexts. An example of a reflection implementation intention would be: "If I receive feedback about my product or service, I will take some time to think it over." Somewhat similarly, the if component (the cue) can be external, such as an environmental feature (e.g., encountering an object, time of day, etc.) or internal, such as a feeling (e.g., boredom) or a motivation (e.g., to be social) (Prestwich et al. 2015). Future research might examine and compare the effectiveness of various implementation intentions.

\subsection{Specificity and level of analysis}

A second issue relating to content that future research might consider is to examine whether implementation intentions are more or less effective for particular gestation activities. In the present study, we treated entrepreneurial action as a single general category, asking about embarking on steps to start a venture. This required participants to identify not only when and where they would take action, but also what action they intended to take. The level of analysis could be changed to specific gestation activities, such as promoting the venture or applying for financing. Doing so would permit researchers to identify the activities for which implementation intentions are more or less effective. Moreover, if implementation intentions are formed for different activities, this also raises the question of whether their effectiveness increases or decreases if multiple implementation intentions are operational at the same time (Prestwich et al. 2015). In addition, the time frame could be varied. The current research applied a 6-month follow-up but time frames could be considerably shorter. It may well be that implementation intentions are more highly correlated with specific actions in the short term; but a corresponding danger is that they become so proximal as predictors that they lose their meaning (Davidsson 2007), and that the importance of distal factors becomes underspecified. With regard to time, a further issue is whether implementation intentions continue to exert their influence over time, and if so, for how long. Gielnik et al. (2015) found that the effects of an action planning training course had worn off after 18 months. Does one implementation intention then suffice, or does the intention need to be reinforced or repeated (Prestwich et al. 2015)?

\subsection{Implementation intentions and uncertainty}

An intriguing research direction concerns the context of the venture in terms of uncertainty and decision-making logic. Although implementation intentions involve the formulation of situational cues, that does not mean that those cues must be certain to arise. The latter would be the case if time, place, and response are set (e.g., "on Wednesday, I will go to the Chamber of Commerce to register my venture"). However, implementation intentions may well be particularly powerful in effectual (Sarasvathy 2001) or creation (Alvarez and Barney 
2007) approaches, because then the cues will require alertness. For example, the effectual principles of being open to surprises and partnerships actually benefit from planning on the action level. Implementation intentions can be helpful in specifying the situational cues to which prospective entrepreneurs should respond, even if the exact time and place cannot be planned. An example is: "whenever someone representing another business expresses an interest in my product or service, I will bring up the topic of possible collaboration." Implementation intentions may thus be a form of planning that functions well in conditions characterized by uncertainty and unpredictability.

\subsection{Induced versus non-induced implementation intentions}

In the vast majority of studies, implementation intentions are induced on the participants by the researchers or by the entity supplying the data (Prestwich et al. 2015). Research on naturally occurring implementation intentions is scarce in the Gollwitzer tradition (for exceptions see Armitage 2009; Brickell et al. 2006; Churchill and Jessop 2010; Rise et al. 2003), although studies of non-induced action plans are common in the wider action planning literature (Carraro and Gaudreau 2013; Hagger and Luszczynska 2014). The question arises as to whether induced implementation intentions are more effective than spontaneous implementation intentions. A further question is whether and when an intervention based on implementation intentions adds value over and above implementation intentions that are spontaneously formed. Spontaneous, self-generated implementation intentions have the advantage of their cues and responses being most salient to each individual's case (Armitage 2009; Wieber and Gollwitzer 2017). Interventions, on the other hand, can encourage participants to engage in a systematic search for critical situations and instrumental action responses (Wieber and Gollwitzer 2017). In contrast, those who form their implementation plans spontaneously may engage in less detailed processing and embrace the first if-then plan that comes to mind (Wieber and Gollwitzer 2017). Spontaneous and experimentally induced planning could potentially interact, as those already forming spontaneous plans may not benefit (at all or as much) from interventions designed to promote planning (Carraro and Gaudreau 2013), an issue we return to in Section 6.6.
Yet another aspect pertaining to induced versus spontaneous, self-generated implementation intentions concerns the if-then form. In the former, the if-then form is guaranteed; in non-induced settings, the if-then form is likely to be implicit. Two studies (Chapman et al. 2009; Oettingen et al. 2000) directly compared the two, and found the induced forms to be more effective. The induced form was argued to be more effective because it had the advantage of cue salience and response automaticity. However, careful examination of the above-mentioned studies shows that the spontaneous condition was disadvantaged in terms of research design. A generic form (implying each Wednesday, compared to next Wednesday for the mandatory if-then form) was supplied by Oettingen et al. (2000) and the instruction by Chapman et al. (2009) made no reference to the "when" and "where" aspects for the spontaneous condition. It is unlikely that self-generated, spontaneous implementation intentions take an explicit if-then form; however, the conditional nature may still be present even if implicit. For example, it is debatable whether "if it is Wednesday, then I will go to the Chamber of Commerce to register my venture" will generate more action than "next Wednesday I will go to the Chamber of Commerce to register my venture."

\subsection{Antecedents of implementation intentions}

As implementation intentions are often studied in settings where they are induced, there is little information on their antecedents. The studies that allowed implementation intentions to form naturally invariably show that goal intention strength is their main determinant (e.g., Brickell et al. 2006; Churchill and Jessop 2010). The current study also shows that to be the case; however, our research design did not include additional antecedents of implementation intentions. As implementation intentions are always in the service of a goal intention, additional antecedents can only be moderators, making it more likely that implementation intentions are formed, rather than being direct causes in themselves. Conscientiousness may be one such candidate, and high reflexivity another: both traits facilitate the consideration of implementation aspects (Thürmer et al. 2015; Wieber et al. 2013). A variable that makes it more likely that implementation intentions are formed (without intervention or induction) may also 
influence the effectiveness of implementation intentions. However, the sign does not need to be the same; for example, Webb et al. (2007) found that implementation intentions were ineffective for those registering high in conscientiousness. This brings us to our next point.

\subsection{Substitution and augmentation}

Whether implementation intentions have stronger substitution or augmentation effects in the context of entrepreneurial goal pursuits merits further attention. In line with the literature (Wieber et al. 2013), our study has shown that implementation intentions are effective if goal intention strength is high, yet we found that they were also effective at lower levels of goal intention strength. Future research might consider additional moderators. In the case of entrepreneurship, experience is a variable of interest, as is self-efficacy, and perceived behavioral control (Rise et al. 2003), and traits such as conscientiousness and impulsiveness (Churchill and Jessop 2010; Gollwitzer et al. 2010). For each, it can be argued that implementation intentions help to compensate for a weakness, or augment a strength. For example, it can be argued that implementation intentions particularly benefit those with little start-up experience, because such intentions force individuals to consider crucial cues and responses. Conversely, it is possible that those with experience formulate betterquality implementation intentions and are therefore likely to take action more effectively. The current study identifies an augmentation effect for goal intention strength and no effects for experience; however, as the points above indicate, there is a wide range of research settings in which the impact of moderators of the relationship between implementation intentions and action could be explored.

An additional possible variation relates to the outcome variable, which might be different to what was used in this empirical work. For example, scholars might investigate whether the presence of implementation intentions makes it more likely that the business becomes successful. Researchers should however bear in mind that implementation intentions concern actions rather than the outcomes of actions, so even a research design focusing on success would need to look at actions as an intermediate step. This also raises the issue of the instrumentality of implementation intentions. An implementation intention makes it more likely that an action is taken, but not every action is necessarily associated with improved performance.

\subsection{Mental contrasting}

A further point relating to the effectiveness of implementation intentions concerns combining them with mental contrasting (Oettingen 2012; Oettingen et al. 2001). Mental contrasting implies juxtaposing visions of desired future outcomes with the obstacles of the present reality. The mental contrasting strategy guarantees a person will be identifying obstacles that are personally relevant, meaning those obstacles can then be specified as the critical cues in the if component of implementation intentions. It also helps to identify instrumental means to overcome those obstacles that can be specified in the then component. Mental contrasting therefore leads to more specific and higher quality if-then plans (Gollwitzer 2014). Mental contrasting trainings have recently been enriched with explicit instructions to form if-then plans. Such mental contrasting with implementation intentions intervention studies reported lasting behavior change (Oettingen et al. 2013).

\section{Conclusion}

Moving beyond motivation and intention, the present study examined action regulation as an explanation of the gap between the formation of entrepreneurial intentions and their subsequent translation into actions. The analysis demonstrates the positive effect of implementation intentions. Although those with weak goal intentions do benefit from having implementation intentions, the results indicate that having implementation intentions is particularly effective for those with strong goal intentions. At the same time, our research agenda illustrates that there is still much to be discovered. Not only is the road to hell paved with good intentions, roads to entrepreneurship are too. Therefore, studying the question of what reduces the intention-action gap will continue to be an important endeavor.

Acknowledgements Michael Gielnik provided highly valuable comments on an earlier version of this manuscript; obviously, any errors remain the responsibility of the authors. 
Open Access This article is distributed under the terms of the Creative Commons Attribution 4.0 International License (http:// creativecommons.org/licenses/by/4.0/), which permits unrestricted use, distribution, and reproduction in any medium, provided you give appropriate credit to the original author(s) and the source, provide a link to the Creative Commons license, and indicate if changes were made.

\section{References}

Achtziger, A., \& Gollwitzer, P. M. (2008). Motivation and volition during the course of action. In J. Heckhausen \& H. Heckhausen (Eds.), Motivation and action (pp. 272-295). London: Cambridge University Press.

Adam, A. F., \& Fayolle, A. (2015). Bridging the entrepreneurial intention-behaviour gap: the role of commitment and implementation intention. International Journal of Entrepreneurship and Small Business, 25(1), 36-54.

Adriaanse, M. A., Vinkers, C. D. W., De Ridder, D. T. D., Hox, J. J., \& De Wit, J. B. F. (2011). Do implementation intentions help to eat a healthy diet? A systematic review and metaanalysis of the empirical evidence. Appetite, 56(1), 183-193.

Aiken, L. S., \& West, S. G. (1991). Multiple regression: testing and interpreting interactions. Thousand Oaks: Sage.

Ajzen, I. (1991). The theory of planned behavior. Organizational Behavior and Human Decision Processes, 50(2), 179-211.

Ajzen, I. (2017). Theory of planned behavior. Retrieved from: http://people.umass.edu/aizen/tpb.html. Last accessed August 132017.

Ajzen, I., Czasch, C., \& Flood, M. G. (2009). From intentions to behavior: implementation intention, commitment, and conscientiousness. Journal of Applied Social Psychology, 39(6), $1356-1372$.

Alvarez, S. A., \& Barney, J. B. (2007). Discovery and creation: alternative theories of entrepreneurial action. Strategic Entrepreneurship Journal, 1(1-2), 11-26.

Armitage, C. J. (2009). Effectiveness of experimenter-provided and self-generated implementation intentions to reduce alcohol consumption in a sample of the general population: a randomized exploratory trial. Health Psychology, 28(5), $545-553$.

Belanger-Gravel, A., Godin, G., \& Amireault, S. (2013). A metaanalytic review of the effect of implementation intentions on physical activity. Health Psychology Review, 7, 23-54.

Bird, B. (1988). Implementing entrepreneurial ideas: the case for intention. Academy of Management Review, 13(3), 442-453.

Brandstätter, V., Heimbeck, D., Malzacher, J. T., \& Frese, M. (2003). Goals need implementation intentions: the model of action phases tested in the applied setting of continuing education. European Journal of Work and Organizational Psychology, 12(1), 37-59.

Brickell, T. A., Chatzisarantis, N. L., \& Pretty, G. M. (2006). Using past behaviour and spontaneous implementation intentions to enhance the utility of the theory of planned behaviour in predicting exercise. British Journal of Health Psychology, 11(2), 249-262.

Brinckmann, J., Grichnik, D., \& Kapsa, D. (2010). Should entrepreneurs plan or just storm the castle? A meta-analysis on contextual factors impacting the business planning-performance relationship in small firms. Journal of Business Venturing, 25(1), 24-40.

Carraro, N., \& Gaudreau, P. (2013). Spontaneous and experimentally induced action planning and coping planning for physical activity: a meta-analysis. Psychology of Sport and Exercise, 14(2), 228-248.

Carsrud, A., \& Brännback, M. (2011). Entrepreneurial motivations: what do we still need to know? Journal of Small Business Management, 49(1), 9-26.

Carter, N. M., Gartner, W. B., \& Reynolds, P. D. (1996). Exploring start-up event sequences. Journal of Business Venturing, 11(3), 151-166.

Carver, C. S., \& Scheier, M. F. (1998). On the self-regulation of behavior. Cambridge: Cambridge University Press.

Chapman, J., Armitage, C. J., \& Norman, P. (2009). Comparing implementation intention interventions in relation to young adults' intake of fruit and vegetables. Psychology and Health, 24(3), 317-332.

Churchill, S., \& Jessop, D. (2010). Spontaneous implementation intentions and impulsivity: can impulsivity moderate the effectiveness of planning strategies? British Journal of Health Psychology, 15(3), 529-541.

Conner, M., \& Armitage, C. J. (1998). Extending the theory of planned behavior: a review and avenues for further research. Journal of Applied Social Psychology, 28(15), 1429-1464.

Davidsson, P. (2006). Nascent entrepreneurship: empirical studies and developments. Foundations and Trends in Entrepreneurship, 2(1), 1-76.

Davidsson, P. (2007). Method challenges and opportunities in the psychological study of entrepreneurship. In J. R. Baum, M. Frese, \& R. A. Baron (Eds.), The psychology of entrepreneurship (pp. 287-323). Mahwah: Lawrence Erlbaum.

Fayolle, A. (2013). Personal views on the future of entrepreneurship education. Entrepreneurship and Regional Development, 25(7-8), 692-701.

Fayolle, A., \& Liñán, F. (2014). The future of research on entrepreneurial intentions. Journal of Business Research, 67(5), 663-666.

Fishbein, M., \& Ajzen, I. (1975). Belief, attitude, intention, and behavior: an introduction to theory and research. Reading: Addison-Wesley Pub.

Frese, M., Mumford, M. D., \& Gibson, C. (2015). Organizational planning. In M. D. Mumford \& M. Frese (Eds.), The psychology of planning in organizations: research and applications (pp. 1-8). New York: Routledge.

Gartner, W. B., Carter, N. M., \& Hills, G. J. (2003). The language of opportunity. In C. Steyaert \& D. Hjorth (Eds.), New movements in entrepreneurship (pp. 103-124). Cheltenham: Edward Elgar.

Gielnik, M. M., Barabas, S., Frese, M., Namatovu-Dawa, R., Scholz, F. A., Metzger, J. R., \& Walter, T. (2014). A temporal analysis of how entrepreneurial goal intentions, positive fantasies, and action planning affect starting a new venture and when the effects wear off. Journal of Business Venturing, 29(6), 755-772.

Gielnik, M. M., Frese, M., Kahara-Kawuki, A., Katono, I. W., Kyejjusa, S., Ngoma, M., et al. (2015). Action and actionregulation in entrepreneurship: evaluating a student training for promoting entrepreneurship. Academy of Management Learning \& Education, 14(1), 69-94. 
Gollwitzer, P. M. (1990). Action phases and mind-sets. In R. M. Sorrentino \& E. T. Higgins (Eds.), Handbook of motivation and cognition: foundations of social behavior (Vol. 2, pp. 53-92). New York: Guildford Press.

Gollwitzer, P. M. (1993). Goal achievement: the role of intentions. European Review of Social Psychology, 4, 141-185.

Gollwitzer, P. M. (1996). Benefits of planning. In P. M. Gollwitzer \& J. A. Bargh (Eds.), The psychology of action: linking cognition and motivation to behavior (pp. 287-312). New York: Guilford Press.

Gollwitzer, P. M. (1999). Implementation intentions: strong effects of simple plans. American Psychologist, 54(7), 493-503.

Gollwitzer, P. M. (2012). Mindset theory of action phases. In P. A. Van Lange, A. W. Kruglanski, \& E. T. Higgins (Eds.), Handbook of theories of social psychology (pp. 526-545). Los Angeles: Sage.

Gollwitzer, P. M. (2014). Weakness of the will: is a quick fix possible? Motivation and Emotion, 38(3), 305-322.

Gollwitzer, P. M., \& Oettingen, G. (2015). The psychology of motivation and actions. In J. D. Wright (Ed.), International encyclopedia of the social \& behavioral sciences (Vol. 15, 2nd ed., pp. 887-893). Oxford: Elsevier.

Gollwitzer, P. M., \& Sheeran, P. (2006). Implementation intentions and goal achievement: a meta-analysis of effects and processes. Advances in Experimental Social Psychology, 38, 69119.

Gollwitzer, P. M., Parks-Stamm, E. J., Jaudas, A., \& Sheeran, P. (2008). Flexible tenacity in goal pursuit. In J. Shah \& W. Gardner (Eds.), Handbook of motivation science (pp. 325341). New York: Guilford Press.

Gollwitzer, P. M., Wieber, F., Myers, A. L., \& McCrea, S. M. (2010). How to maximize implementation intention effects. In C. R. Agnew, D. E. Carlston, W. G. Graziano, \& J. R. Kelly (Eds.), Then a miracle occurs: focusing on behavior in social psychological theory and research (pp. 137-161). New York: Oxford University Press.

Greve, W. (2001). Traps and gaps in action explanation: theoretical problems of a psychology of human action. Psychological Bulletin, 108(2), 435-451.

Hagger, M. S., \& Luszczynska, A. (2014). Implementation intention and action planning interventions in health contexts: state of the research and proposals for the way forward. Applied Psychology. Health and Well-Being, 6(1), 1-47.

Hayes, A. F. (2013). Introduction to mediation, moderation, and conditional process analysis: a regression-based approach. New York: Guildford Press.

Honig, B. (2004). Entrepreneurship education: toward a model of contingency-based business planning. Academy of Management Learning \& Education, 3(3), 258-273.

Kautonen, T., Van Gelderen, M. W., \& Fink, M. (2015). Robustness of the theory of planned behavior in predicting entrepreneurial intentions and actions. Entrepreneurship Theory and Practice, 39(3), 655-674.

Krueger, N. (2009). Entrepreneurial intentions are dead: long live entrepreneurial intentions. In A. L. Carsrud \& M. Brännback (Eds.), Understanding the entrepreneurial mind (pp. 51-72). New York: Springer.

Lerner, D. A., Hunt, R. A., \& Dimov, D. (2018). Action! Moving beyond the intendedly-rational logics of entrepreneurship. Journal of Business Venturing, 33(1), 52-69.
Lichtenstein, B. B., Carter, N. M., Dooley, K. J., \& Gartner, W. B. (2007). Complexity dynamics of nascent entrepreneurship. Journal of Business Venturing, 22(2), 236-261.

Locke, E. A., \& Latham, G. P. (1990). A theory of goal setting and performance. Englewood Cliffs: Prentice Hall.

McClelland, D. C., Atkinson, J. W., Clark, R. A., \& Lowell, E. L. (1953). The achievement motive. New York: AppletonCentury-Crofts.

Obschonka, M., \& Stuetzer, M. (2017). Integrating psychological approaches to entrepreneurship: the entrepreneurial personality system (EPS). Small Business Economics, 49(1), 203231.

Obschonka, M., Silbereisen, R. K., Cantner, U., \& Goethner, M. (2015). Entrepreneurial self-identity: predictors and effects within the theory of planned behavior framework. Journal of Business and Psychology, 30(4), 773-794.

Oettingen, G. (2012). Future thought and behavior change. European Review of Social Psychology, 23, 1-63.

Oettingen, G., Hönig, G., \& Gollwitzer, P. M. (2000). Effective self-regulation of goal attainment. International Journal of Educational Research, 33(7), 705-732.

Oettingen, G., Pak, H., \& Schnetter, K. (2001). Self-regulation of goal setting: turning free fantasies about the future into binding goals. Journal of Personality and Social Psychology, 80, 736-753.

Oettingen, G., Wittchen, M., \& Gollwitzer, P. M. (2013). Regulating goal pursuit through mental contrasting with implementation intentions. In A. E. Locke \& G. Latham (Eds.), New developments in goal setting and task performance (pp. 523-548). New York: Routledge.

Parker, S. C. (2009). The economics of entrepreneurship. Cambridge: Cambridge University Press.

Podsakoff, P. M., MacKenzie, S. B., Lee, J. Y., \& Podsakoff, N. P. (2003). Common method biases in behavioral research: a critical review of the literature and recommended remedies. Journal of Applied Psychology, 88, 879-903.

Prestwich, A., Sheeran, P., Webb, T. L., \& Gollwitzer, P. (2015). Implementation intentions. In M. Conner \& P. Norman (Eds.), Predicting health behavior (3rd ed., pp. 321-357). New York: McGraw Hill.

Rauch, A., \& Hulsink, W. (2015). Putting entrepreneurship education where the intention to act lies: an investigation into the impact of entrepreneurship education on entrepreneurial behavior. Academy of Management Learning \& Education, 14(2), 187-204.

Reuel Johnmark, D., Munene, J. C., \& Balunywa, W. (2016). Robustness of personal initiative in moderating entrepreneurial intentions and actions of disabled students. Cogent Business \& Management, 3(1), 1-16.

Rise, J., Thompson, M., \& Verplanken, B. (2003). Measuring implementation intentions in the context of the theory of planned behavior. Scandinavian Journal of Psychology, 44(2), 87-95.

Rogelberg, S. G., \& Stanton, J. M. (2007). Understanding and dealing with organizational survey nonresponse. Organizational Research Methods, 10(2), 195-209.

Sarasvathy, S. D. (2001). Causation and effectuation: toward a theoretical shift from economic inevitability to entrepreneurial contingency. Academy of Management Review, 26(2), 243-263. 
Schlaegel, C., \& Koenig, M. (2014). Determinants of entrepreneurial intent: a meta-analytic test and integration of competing models. Entrepreneurship Theory and Practice, 38(2), 291-332.

Schüz, B., Sniehotta, F. F., Mallach, N., Wiedemann, A. U., \& Schwarzer, R. (2008). Predicting transitions from preintentional, intentional and actional stages of change. Health Education Research, 24(1), 64-75.

Shane, S., \& Venkataraman, S. (2000). The promise of entrepreneurship as a field of research. Academy of Management Review, 25(1), 217-226.

Shapero, A., \& Sokol, L. (1982). Social dimensions of entrepreneurship. In C. Kent, D. Sexton, \& K. Vesper (Eds.), The encyclopedia of entrepreneurship (pp. 72-90). Englewood Cliffs: Prentice Hall.

Sheeran, P. (2002). Intention-behavior relations: a conceptual and empirical review. European Review of Social Psychology, 12(1), 1-36.

Sheeran, P., Webb, T. L., \& Gollwitzer, P. M. (2005). The interplay between goal intentions and implementation intentions. Personality and Social Psychology Bulletin, 31(1), 87-98.

Sniehotta, F. F. (2009). Towards a theory of intentional behaviour change: plans, planning, and self-regulation. British Journal of Health Psychology, 14(2), 261-273.

Sniehotta, F. F., Schwarzer, R., Scholz, U., \& Schüz, B. (2005). Action planning and coping planning for long-term lifestyle change: theory and assessment. European Journal of Social Psychology, 35(4), 565-576.

Thürmer, J. L., Wieber, F., \& Gollwitzer, P. M. (2015). Planning high performance: Can groups and teams benefit from implementation intentions? In M. D. Mumford \& M. F. Frese (Eds.), The psychology of planning in organizations: Research and applications (pp. 123-145). New York: Routledge.

Toli, A., Webb, T. L., \& Hardy, G. E. (2016). Does forming implementation intentions help people with mental health problems to achieve goals? A meta-analysis of experimental studies with clinical and analogue samples. British Journal of Clinical Psychology, 55(1), 69-90.

Van Gelderen, M. W., Kautonen, T., \& Fink, M. (2015). From entrepreneurial intentions to actions: self-control and actionrelated doubt, fear, and aversion. Journal of Business Venturing, 30(5), 655-673.
Van Hooft, E. A., Born, M. P., Taris, T. W., Van der Flier, H., \& Blonk, R. W. (2005). Bridging the gap between intentions and behavior: implementation intentions, action control, and procrastination. Journal of Vocational Behavior, 66(2), 238-256.

Vroom, V. H. (1964). Work and motivation. New York: Wiley.

Webb, T. L., \& Sheeran, P. (2006). Does changing behavioral intentions engender behavior change? A meta-analysis of the experimental evidence. Psychological Bulletin, 132(2), 249-268.

Webb, T. L., Christian, J., \& Armitage, C. J. (2007). Helping students turn up for class: does personality moderate the effectiveness of an implementation intention intervention? Learning and Individual Differences, 17, 316-327.

Wieber, F., \& Gollwitzer, P. M. (2017). Planning and the control of action-how spontaneous and strategic use of goal-related knowledge supports goal attainment. In P. Meusburger (Ed.), Knowledge and space: Vol. 9. Knowledge and action (pp. 169-183). New York: Springer Science + Business Media.

Wieber, F., Thürmer, J. L., \& Gollwitzer, P. M. (2013). Intentional action control in individuals and groups. In G. Seebass, M. Schmitz, \& P. M. Gollwitzer (Eds.), Acting intentionally and its limits: individuals, groups, institutions. Berlin: De Gruyter.

Wieber, F., Thürmer, J. L., \& Gollwitzer, P. M. (2015). Promoting the translation of intentions into action by implementation intentions: behavioral effects and physiological correlates. Frontiers in Human Neuroscience, 9, 395. https://doi. org/10.3389/fnhum.2015.00395.

Williams, L. J., Vandenberg, R. J., \& Edwards, J. R. (2009). Structural equation modeling in management research: a guide for improved analysis. Academy of Management Annals, 3(1), 543-604.

Yu, J., \& Cooper, H. (1983). A quantitative review of research design effects on response rates to questionnaires. Journal of Marketing Research, 20(1), 36-44.

Ziegelmann, J. P., Luszczynska, A., Lippke, S., \& Schwarzer, R. (2007). Are goal intentions or implementation intentions better predictors of health behavior? A longitudinal study in orthopedic rehabilitation. Rehabilitation Psychology, 52(1), 97-102. 